\title{
Public Sector Responses to Jail Mental Health: A Review with Recommendations for Future Research
}

\author{
Ronald Helms ${ }^{1}$, Ricky S. Gutierrez ${ }^{2}$, Debra Reeves-Gutierrez ${ }^{3}$ \\ ${ }^{1}$ Western Washington University, Bellingham, Washington, USA \\ ${ }^{2}$ California State University, Sacramento, Sacramento, California, USA \\ ${ }^{3}$ Alliant International University, San Francisco, California, USA \\ Email: Ronald.Helms@wwu.edu, rickyg@csus.edu, dreeves@alliant.edu
}

Received October $9^{\text {th }}$, 2013; revised November 21 ${ }^{\text {st }}$ 2013; accepted December $13^{\text {th }}, 2013$

\begin{abstract}
Copyright (C) 2014 Ronald Helms et al. This is an open access article distributed under the Creative Commons Attribution License, which permits unrestricted use, distribution, and reproduction in any medium, provided the original work is properly cited. In accordance of the Creative Commons Attribution License all Copyrights (c) 2014 are reserved for SCIRP and the owner of the intellectual property Ronald Helms et al. All Copyright (C) 2014 are guarded by law and by SCIRP as a guardian.
\end{abstract}

The history of public mental health intervention in the US has been uneven and in some instances is characterized by a strong overtone of neglect. While clinical research in primarily private settings has generated findings that give a strong sense of "what works" in mental health diagnosis and treatment, this review pays special attention to the distribution of mental illness among jailed populations. Local jail systems house a substantial number of mentally challenged individuals but receive less attention than is warranted given their numbers. This paper concludes with a plea for research with a focus on the community determinants of mental health systems in order to enhance delivery of services and increase the likelihood of reaching those most in need of mental health treatment.

Keywords: Mental Health; Jails; Community Mental Health; Mental Health Research; Society and Mental Health

\section{Introduction}

What seems to work in the field of mental health treatment? Researchers, primarily in the US, have documented through a substantial number of published studies, a series of answers to this question. In the research note that follows, we summarize the field of research with the intent to bring into a single space, a brief on the history of mental health intervention as well as findings regarding "what works" from the scholarly literature. Since so many mentally ill individuals are discovered through the intake process at county jails throughout the country, and become subsequently "consumers of services" while incarcerated in local jail facilities, we focus special attention on this critical aspect of mental health populations and delivery systems. Doing so will allow for an assessment of questions that are less clear cut and help direct attention to where research should focus in light of austere fiscal conditions and shifting parameters of privatized support for intervention in the mental health field.

\section{Review of the Literature}

\section{The US Experience with Mental Illness}

Mental health care at the level of the individual has been the focus of concern throughout a substantial portion of American history, and in particular during the past 150 years. The scholarly literature features a wide range of studies on mental health issues, primarily focused on individual-level experiences, diagnostic issues, and treatment effects. Although there is docu- mented evidence of substantial rates of occurrence of mental illness in the developmental stages of our nation, the first attempt to officially document the extent of mental illness and mental retardation occurred with the inclusion of the categories insane and idiotic during the collection of the Census of 1840. By the late 1800s mental health crusaders such as Dorothy Dix $(1843 ; 1975)$ were instrumental in establishing and expanding the state hospital system for the treatment and care of mentally ill patients, thereby relieving to some extent, the burden of care for these populations to the ill-equipped almshouses and local jails (Torrey, Kennard, Eslinger, Lamb, \& Pavle, 2010). Between 1850 and 1869, 35 new state hospitals were established, and by 1890 another 59 additional state hospitals were established. Those institutions being built after 1870 were substantially larger than those built earlier in order to accommodate more patients who represented an expanding scope of mental and physical of conditions (Staples, 1990). The process of establishing state hospitals for the mentally ill, largely initiated by Dix, continued to evolve and expand throughout the early 1950 s, reaching its zenith by mid-decade.

At the high point, state facilities for involuntary commitments of the mentally ill housed approximately 557,000 people (Kerle, 2004). After years of controversy and documented abuse of mental patients confined to such facilities, a federal court ruling issued in Wyatt v. Stickney (1972) led to the widespread deinstitutionalization of those mentally ill persons involuntarily committed to state institutions and who did not fit within a narrowly defined description, to wit, the presence of documented evidence that institutional confinement was re- 
quired either for the safety of the person or for the safety of the community. As a result of this ruling, many states chose to release large numbers of mentally ill patients into their local communities prior to the development of adequate communitybased mental health treatment services (e.g., ongoing medication, periodic counseling, and targeted therapy). The mental health system in the United States went from being primarily an institutional service program to becoming principally a community care operation. Virtually overnight, this system went from what had been a state- or county-provider system to a vast array of behavioral health networks that are typically organized as not-for-profit agencies (Cox, Morschhauser, Banks, and Stone, 2001). Thus, Dorothea Dix began her campaign for mental health care reform and the decriminalization of mental illness during the 1840s, public policy concerning the responsibility for and care of the mentally ill has been a topic of great ongoing debate and occasional sharp controversy (Torrey et al. 2010).

By the turn of the century, the mental hygiene movement was taking root and gaining significant ground across the country. Clifford Beers, a researcher and gifted writer, drew public attention to mental illness by shocking readers with a graphic account of hospital conditions in his famous book, A Mind that Found Itself (1908). Another historical factor that is noteworthy is the systematic screening of immigrants at Ellis Island for signs of mental illness and/or mental retardation. The high incidence of mental disorders among immigrants broadened public recognition of mental illness as a national health problem (Grimes, 1974). It wasn't until 1930 however, that the US Public Health Service (PHS) established the Narcotics Division, later re-named the Division of Mental Hygiene, bringing together research and treatment programs to combat drug addiction and to study the prevalence of mental/nervous disorders and the efficiency of interventions developed to treat them.

During the nation's involvement in World War II severe shortages of professional mental health personnel translated into a deficit in treatment providers who were able to interpret the symptoms of mental illness (Grimes, 1974). One truly unfortunate result of the interruption of active research and treatment during this time was that the mental health field lagged behind other fields of medical science and public health. Eventually, a national mental health program was proposed, forming the foundation of what would become the National Mental Health Act of 1946. This was a key development in the effort to have the federal government recognize and respond to mental health problems in the nation. Subsequent to this legislation the number of institutionalized mentally ill persons in the US rose dramatically to over one half million hospitalized individuals by 1955 .

In response to over-burdened state mental institutions, legislation dictated that only those who present a danger to themselves or the public would remain institutionalized. Thus, over the course of subsequent years the number of patients with mental illness being treated in an institutional setting dropped dramatically, so that today there only about 57,000 persons held in state mental health hospitals, sometimes against their own will, the result of a court ruling permitting involuntary confinement. In terms of committed bed space, Lamb and Weinberger (2005: p. 529) assert that "by the year 2000, the number of state hospital beds had dropped from its high in 1955 of 339 per 100,000 to just 22 per 100,000 on any given day.” The unfortunate culmination of events following Wyatt v. Stickney (1972), and given the clearly insufficient availability of mental health treatment services, this resulted in the emergence of the criminal justice system as a default primary provider of mental health services in local communities (Perez, Leifman, \& Perez, 2003).

It is ironic that while it has been over a century and a half since Dorothea Dix’ observations presented to the Massachusetts legislature in 1843 about the inhumanity and inappropriateness of incarcerating the insane (Dix, 1843), the incarceration of the mentally ill today remains a widespread occurrence in the US. The utilization of jails to house mentally ill defendants has been documented by academic researchers in recent years using several alternative measures: data taken at the point of intake processing indicating a recent [documented] history or symptoms of a mental health problem that must have occurred in the 12 months prior to the interview; or, a recent history of mental health problems [that] included a clinical diagnosis or treatment by a mental health professional. Symptoms of a mental disorder have, generally speaking, been based on criteria specified in the Diagnostic and Statistical Manual of Mental Disorders, Fourth Edition (DSM-IV) (James \& Glaze, 2006: p. 1). Under this classification, contemporary studies indicate that $21 \%$ of arrestees processed in the local jails across the US reported a recent history of mental health intervention, and $60 \%$ of jail detainees exhibited symptoms that are characteristic of some level of mental disorder (Cornelius, 2008; James \& Glaze, 2006).

According to recent evidence reported by the National Institute of Mental Health, approximately 26.2 percent of the adult US population suffers from a diagnosable mental health disorder in any given year (National Institute of Mental Health 2009) ${ }^{1}$. While many of those who suffer from mental disorders receive professional care and treatment in their community (services that are often covered in private health plans), other cases are newly discovered through the process of arrest for criminal activity and the related criminal justice processing that occurs consequent to arrest. A study conducted by the Bureau of Justice Statistics (2006) revealed that $64 \%$ of persons incarcerated in jails had a discernible mental health problem. This represented 479,900 mentally ill individuals housed in jail facilities in the US. This alarming figure was also reported by Cornelius in his study of the jail population in 2006; he reported on the basis of his observations that $64 \%$ of jail residents suffered from some form of diagnosable mental health affliction (Cornelius, 2008).

In the United States, the National US Jail Census (United States Department of Justice, 1999) documents an uneven pattern of mental health problems and institutional responses to the concentrated populations of mentally ill individuals housed in local jails. In a study of 25 New York jails conducted by Cox et al. (2001), it was noted that irrespective of age or gender those persons who are recipients of mental health services are more likely than persons in the general population to spend at least one night in a local jail. As noted by Goslin (2008), "there has evolved a vicious cycle of neglect, abandonment, indignity, cruel and inhuman treatment, and punishment of persons with mental illness” (p. 906). The prevalence of mental health disorders in the US has been well documented in the scholarly research; however, policies to date authorizing and resourcing mental health treatment for persons involved in the criminal

${ }^{1}$ This percentage figure includes all categories of diagnosable mental health conditions. 
justice continuum have fallen far short of ensuring adequate and equitable services to the mentally ill jail residents.

Mental health research has focused nearly exclusively on individual-level determinants and consequences, while leaving largely unexplored the community-level correlates of mental health treatment, particularly in the local jail environment. This is a surprising omission from the literature since the criminal justice system has become a key repository for the mentally ill as well as a major component in the delivery of mental health services (Holcomb \& Ahr, 1988; Kalinich, Embert, \& Senese, 1988; Steadman, Morrissey, \& Robbins, 1985; Hardy, 1984; Gibbs, Maiello, Kolb, Garofalo, Aidler, \& Costello, 1983; Teplin, 1984; Gibbs, 1982). While the numbers of involuntarily committed patients have dropped steadily in state-run hospitals, local jails have increasingly become de facto providers of temporary housing and emergency assistance for many mentally ill persons. This situation has contributed in diverse ways to evolving security concerns for jail administrators who have a primary responsibility to maintain security and safety for all those arrestees under the jail's custodial care.

The existing scholarly literature examining the prevalence of mental illness within correctional populations has generally been established using any one of three methods: 1) face-toface clinical assessments of incarcerated persons; 2) self-reporting by incarcerated persons; and 3) via a system of matching incarceration records with mental health care records (Cox et al., 2001). Managing a large population of mentally ill detainees presents serious concerns for jail administrators since these individuals are, according to Ruddell (2010), often disruptive to the jail milieu and normally require enhanced supervision, direction, and treatment, as well as protection from predatory inmates. Ruddell's report documented the fact that $9.3 \%$ of jail inmates with mental health problems were physically injured during some type of inmate-to-inmate altercation, and 19\% were charged with institutional infractions. Complicating the picture, the mentally ill are often caught in a cyclic pattern involving going from living on the streets, to incarceration in local jails, and then back to the streets again. These observations about local jail populations and the special troubles presented to administration associated with the presence of often undiagnosed and untreated mental illness cases invite additional scrutiny and analysis. Accordingly, research beckons in the area of documenting patterns of mental illness and mental health treatment capacity in county jail systems throughout the United States, along with identifying the community correlates associated with local-level jail capacity for managing mentally ill detainees.

For the purposes of this review, we highlight the DSM IV (1994) definition of mental disorder, namely, a clinically significant behavioral or psychological syndrome or pattern that occurs in an individual and that is associated with present distress (e.g., a painful symptom) or disability (i.e., impairment in one or more important areas of functioning) or with a significantly increased risk of suffering death, pain, disability, or an important loss of freedom. The following section offers a summary of literature on mental illness and treatment, documenting the relative absence of systematic research on community sources of jail mental health response.

\section{Academic Research Findings Relating to Mental Illness}

The Bureau of Justice Statistics (Bureau of Justice Statistics
2009) offers descriptive evidence that mental illness among those incarcerated in local jails constitutes an important problem in many areas of the country. As noted in the 2006 Bureau of Justice Statistics (BJS) report, some degree of mental illness was documented in $60 \%$ of jail inmates, a percentage that is substantially greater than figures reported for those incarcerated in federal and state prisons. According to this report, approximately $24 \%$ of jail inmates self-reported at least one symptom associated with a psychotic disorder. Among arrestees, those exhibiting mental disorders experienced the highest rate of dependence on or abuse of alcohol or drugs (76\% v. 53\% for inmates without mental impairment). Gender has a bearing on the nexus of mental health services and incarceration as well. In the Cox et al. (2001) study, it was noted that female recipients of mental health services across all age groups were at a greater elevated risk for incarceration compared with the general population than the elevated risk of incarceration for male mental health recipients. Similarly, the 2006 BJS report documented that some type of mental disorder was documented in $75 \%$ of female inmates and $63 \%$ of male inmates. Unfortunately, according to the BJS report, only 1-in-6 jail inmates experiencing a mental health condition had received treatment since their confinement. Such summary information provides a foundation for claims that mental illness and substance abuse are problems that permeate the contemporary offender population housed in U.S. jails throughout the country.

Local jail administrators face difficult problems linked to a high level of co-occurring disorders or dual diagnoses. As noted by Peters, LeVasseur and Chandler (2004: p. 563), "individuals with co-occurring disorders frequently cycle through acute care facilities in the community and are increasingly placed in jails or prisons.” A critical concern in treating inmates who are dually diagnosed is that service providers are often confronted with the problem of which symptoms to treat first as one often precipitates the other. As documented by Edens, Peters, and Hills (1997), this detainee population often has more significant psychosocial problems, more difficulty adjusting to institutional arrangements, and more pronounced cognitive and functional deficits when compared to other jail detainees. Alcohol and drug detoxification must preclude treating any form or mental disorder, and generally is not effectively addressed in a punitive environment. In many cases, dual diagnosis goes undetected and results in frequent misdiagnosis, the development of ineffective treatment plans, and poor treatment outcomes (Drake, Alterman, \& Rosenberg, 1993; Peters \& Steinberg, 2000; Teague, Schwab, \& Drake, 1990). While there has been a great deal of research on the linkages between drug and alcohol abuse and the commission of crime, less research has been undertaken that documents the proximal links between these factors and mental illness. Unfortunately, for many mentally ill inmates their mental health status remains undiagnosed until a chargeable crime is committed. At the time of intake and booking, screening efforts may reveal the presence of mental disorders, but all too often local jail facilities do not possess adequate capacity to address mental illness even if it is diagnosed accurately during the intake process. Moreover, even when referred to county mental health services, these agencies may view incarcerated individuals as bad organizational risks to take on as clients since behaviors that led the mentally ill into the criminal justice system are often viewed as not being amenable to treatment (Kalinich et al., 1988). Further, when compared with the general population, the risk of incarceration increases 
as recipients of mental health services progress in age (Cox et al., 2001).

The prevalence of a high number of detainees with mental health symptoms is also reflective of the emerging role being played by local jails in their respective local communities. Jails are locally operated correctional facilities that receive offenders after an arrest and hold them for relatively short periods of time (up to 12 months) while awaiting arraignment and trial, and hold those who are convicted but not yet sentenced, awaiting possible conviction and subsequent sentencing, or awaiting transfer to a state prison (Cox et al., 2001). Among other functions, local jails hold mentally ill persons pending their movement to appropriate mental health facilities. While jails also hold inmates sentenced to short terms, state and federal prisons hold offenders who typically are convicted and sentenced to serve one year or more. In general, because of the longer period of incarceration, prisons provide greater opportunity for inmates to receive a clinical mental health assessment, develop an appropriate diagnosis, and receive targeted treatment by qualified mental health staff.

Fiscal support for community mental health services remains a low priority for most state legislators despite the fact that local jails confine offenders who suffer from a variety of mental disorders and also commit a variety of non-violent crimes. In addition, the mandate for county mental health services provided to persons incarcerated in local jails has not been accompanied by additional fiscal or personnel services (Kalinich et al., 1988). As noted by Clear, Cole and Reisig (2011: p. 148), “only $3 \%$ of the violent behavior in the US is linked to mental disorders and people with mental illness are more likely to be victims of crime rather than perpetrators of violence.” Yet once arrested for a criminal offense and booked into the county jail, the mentally disordered offender must be cared for and dealt with by the jail staff. Unfortunately, some jails have large populations of detainees with mental disorders, and these facilities have become the largest and most convenient location for mental health services in the community. If an offender is mentally ill, the facts that take precedence are that a crime has been committed, the offender is in custody, and his or her welfare and safety then becomes the responsibility of the local jail until the case is adjudicated in the courts. An important factor in this process that should not be overlooked is the political posture that sheriffs typically must observe in that their appointments are governed by voters, and a correlative desire to be viewed by voters as "crime fighters" rather than managers of mental health services for inmates (Kalinich et al., 1988). Over the past two decades there has been an increasing level of concern within the correctional field about problems arising from the jailing of large populations of mentally ill offenders (Walsh \& Holt, 1999; Torrey et al., 2010).

While the scholarly literature on jails has continued to expand, it has yet to address these types of concerns sufficiently. Moreover, the literature has yet to offer an empirical account of the effects localized community institutions may have on jail mental health screening and response potential. Given a history of fiscal austerity combined with resistance to developing comprehensive service facilities, jails operations have been severely limited in the provision of internal mental health services. Unfortunately, external (drop in) mental health services provided within jail settings have not fared much better. This is due in part to correctional officers' perceived concern that their authority and discretion in managing inmates may be overridden by credentialed county mental health professionals (Kalinich et al., 1988).

With the foregoing summarization of literature in mind, we note that despite growing awareness of mental health concerns, virtually no research to date has used an empirical approach to study community correlates of jail mental health services. Put differently, we know very little about the environmental contexts that are most supportive of mental health services delivery for mentally ill people in communities throughout the US. And in particular, we have little insight into conditions that might improve delivery of mental health services in today's jail systems, despite having a well-documented and lengthy history of ignoring of the needs of the mentally ill, and also a history of uneven attention and in the worst situations, neglect and even outright abuse of the mentally ill that is also part of our collective history. This is a deplorable situation since local jails are such prominent features in the management of mental illness in virtually every community in the US today. We turn now to a brief discussion and conclusions with the hope of bringing new attention to this field of academic and clinical research.

\section{Recommendations}

The foregoing review demonstrates the need for a practical approach to intervention in the mental health field. A great deal is known from a clinical standpoint regarding what seems to work in stabilizing and otherwise assisting mentally challenged individuals. What is less well understood are the social circumstances that make intervention more or less accessible to those experiencing disorders, who however lack economic means to obtain assistance with their mental health condition. This area of research needs to be the focus of attention given the crisis facing governments who are often charged with dealing with the mentally disordered in both public health and criminal justice contexts. Unfortunately, the research does not at this point have a strong voice in this aspect of policymaking and fiscal prioritization. We urge researchers to follow in the footsteps, do what has been done with regard to a variety of other policy themes and focus on the structural and institutional contexts that favor or otherwise discourage mental health resourcing.

We note in this context what has been recently articulated in another research report (Helms, Gutierrez, \& Reeves-Gutierrez, under review), who note that "despite sociologically oriented studies documenting a wide range of structural and institutional correlates of diverse outcomes such as suicide, homicide, police strength, prison admissions, prison population size, and overall correctional expenditures, among many additional social and criminal justice outcomes, contributions to the literature have thus far not turned their attention to the correlates of mental health resourcing” (p. 3). Their research into jail delivery systems for managing care for the mentally ill continues by asking the following: "How well-prepared are local jails to manage the full range of mentally ill defendants who are arrested and detained in them? Despite widespread recognition that mental illness is a serious health concern throughout the US (National Institute of Mental Health, 2009), and that it is also a condition experienced by many who are held in local jail facilities (Bureau of Justice Statistics, 2006 \& 2009; Cornelius, 2008), very little empirical research has been conducted to assess the readiness of local jails to address the mental illness concerns with which they are routinely confronted. This is indeed unfortunate since the county jail is typically the largest facility in any local 
community for housing the mentally ill (Kerl, 2004), and thus represents one of the key mechanisms available for the public management of mental illness in communities throughout the country" (p. 3).

A focused approach in this area of research is critical at this point since public policy seems oriented to other social concerns while federal and local legislators are now facing an ongoing and quite serious revenue crisis. Even as this has developed, the private sector continues to operate under perverse profit incentives that often overlook the most critically affected and least capable citizens in need of mental health intervention. In light of this, we strongly encourage social researchers to consider this broader focus on mental health resourcing and the social correlates of support for a stronger public mental health approach across communities.

\section{REFERENCES}

Ala, M. D. (1972). Wyatt v. stickney.

Beers, C. W. (1908). A mind that found itself. Pittsburgh, PA: University of Pittsburgh Press.

Bureau of Justice Statistics (2006). Mental health problems of prison and jail inmates. US Department of Justice, Office of Justice Programs.

Bureau of Justice Statistics (2009). http://bjs.ojp.usdoj.gov/

Clear, T., Cole, G., \& Reisig, M. (2011). American corrections (9th ed.) Belmont, CA: Wadsworth, Cengage Learning.

Cornelius, G. F. (2008). The American jail: Cornerstone of modern corrections. Upper Saddle River, NJ: Pearson Education, Inc.

Cox, J. F., Morschauser, P. C., Banks, S., \& Stone, J. L. (2001). A fiveyear population study of persons involved in the mental health and local correctional systems: Implications for service planning. The Journal of Behavioral Health Services \& Research, 28, 177-187. http://dx.doi.org/10.1007/BF02287460

Dix, D. L. (1975) On behalf of the insane poor: Selected reports 18421862. New York, NY: Ayer Co. Publishers, Inc.

Dix, D. L. (1843). Memorial to the legislature of Massachusetts. http://www.archive.org/stream/memorialtolegisl00dixd\#page/n4/mod e/1up

Drake, R. E., Alterman, A. I., \& Rosenberg, S. R. (1993). Detection of substance use disorders in severely mentally ill patients. Community Mental Health Journal, 29, 175-192. http://dx.doi.org/10.1007/BF00756343

Edens, J. F., Peters, R. H., \& Hills, H. A. (1997). Treating prison inmates with co-occurring disorders: An integrative review of existing programs. Behavioral Sciences and the Law, 15, 439-457. http://dx.doi.org/10.1002/(SICI)1099-0798(199723/09)15:4<439::AI D-BSL282>3.0.CO;2-X

Gibbs, J. (1982). On demons and goals: A summary and review of investigations concerning the psychological problems of jail prisoners. In C. Dunn, \& H. J. Steadman (Eds.), Mental health services in local jails: A report on a special national workshop. Rockville, MD: National Institute of Mental Health.

Gibbs, J., Maiello, K., Kolb, J., Garofalo, F., Aidler, F., \& Costello, S. (1983). Stress, setting, and satisfaction: The final report of the manjail transactions project. Unpublished report. Washington DC: National Institute of Justice.

Goslin, L. O. (2008). "Old" and "new" institutions for persons with mental illness: Treatment, punishment or preventive confinement. Public Health, 122, 906-913.

http://dx.doi.org/10.1016/j.puhe.2007.11.003

Grimes, J. M. (1974). Institutional care of mental patients in the United
States. Chicago, IL: Grimes Publishing.

Hardy, S. L. (1984). Dealing with the mentally and emotionally disturbed. Corrections Today, 126, 16-18.

Helms, R., Gutierrez, R., \& Reeves-Gutierrez, D. (2013). Jail mental health services: A conceptual and empirical study of social determinants. (Under Review).

Holcomb, W. R., \& Ahr, P. R. (1988). Arrest rates among young adult psychiatric patients treated in inpatient and outpatient settings. Hospital and Community Psychiatry, 39, 52-57.

Irwin, M., Tolbert, C., \& Lyson, T. (1999). There’s no place like home: Nonmigration and civic engagement. Environment and Planning, 31, 2223-2238. http://dx.doi.org/10.1068/a312223

James, D. J., \& Glaze, E. (2006). Mental health problems of prison and jail inmates. http://bjs.ojp/usdoj.gov/content/pub/pdf/mhppji.pdf

Kerle, K. E. (2004). Exploring jail operations. Hagerstown, MD: American Jails Association.

Kalinich, D., Embert, P., \& Senese, J. D. (1988). Integrating community mental health services into local jails: A policy perspective. Policy Studies Review, 7, 660-670. http://dx.doi.org/10.1111/j.1541-1338.1988.tb00861.x

Lamb, H. R., \& Weinberger, L. E. (2005). The shift of psychiatric inpatient care from hospitals to jails and prisons. Journal of the American Academy of Psychiatry the Law, 33, 529-534.

National Institute of Mental Health (2009). http://www.nimh.nih.gov/health/topics/statistics/index.shtml on 7/13/2010

Perez, A., Leifman, S., \& Estrada, A. (2003). Reversing the criminalization of mental illness. Crime and Delinquency, 49, 62-78. http://dx.doi.org/10.1177/0011128702239236

Peters, R. H., LeVasseur, M. E., \& Chandler, R. K. (2004). Correctional treatment for co-occurring disorders: Results of a national survey. Behavioral Sciences and the Law, 22, 563-584. http://dx.doi.org/10.1002/bsl.607

Peters, R. H., \& Steinberg, M. L. (2000). Substance abuse treatment services in US prisons. In D. Shewan, \& J. Davies (Eds.), Drugs and Prisons (pp. 89-116). London: Harwood.

Ruddell, R. (2010). American jails: A retrospective examination. Richmond Kentucky: Newgate Press.

Staples, W. G. (1990). Castles of our conscience: Social control and the American state, 1800-1985. New Brunswick, NJ: Rutgers University Press.

Steadman, H. J., Morrissey, J. P., \& Robbins, P. C. (1985). Reevaluating the custody-treatment conflict paradigm in correctional mental health settings. Criminology, 23, 165-179. http://dx.doi.org/10.1111/j.1745-9125.1985.tb00331.x

Teague, G. B., Schwab, B., \& Drake, R. E. (1990). Evaluating services for young adults with severe mental illness and substance abuse disorders. Arlington, VA: National Association of State Mental Health Program Directors.

Teplin, L. (1984). Criminalizing mental disorder: The comparative arrest rate of the mentally ill. American Psychologist, 39, 794-803. http://dx.doi.org/10.1037/0003-066X.39.7.794

Torrey, E. F., Kennard, A. D., Eslinger, D., Lamb, R., \& Pavle, J. (2010). More mentally ill persons are in jails and prisons than in hospitals. Arlington/Alexandria, VA: National Sheriffs Association and Treatment Advocacy Center.

United States Department of Justice. Bureau of Justice Statistics. National Jail Census (1999). ICPSR03318-v3. Ann Arbor, MI: Inter-university Consortium for Political and Social Research [distributor]. http://dx.doi.org/10.3886/ICPSR03318

Walsh, J., \& Holt, D. (1999). Jail diversion for people with psychiatric disabilities: The sheriffs' perspective. Psychiatric Rehabilitation Journal, 23, 153-160. http://dx.doi.org/10.1037/h0095176 